\title{
Temporal regulation of a paired-like homeodomain repressor/TLE corepressor complex and a related activator is required for pituitary organogenesis
}

\author{
Jeremy S. Dasen, ${ }^{1}$ Juan-Pedro Martinez Barbera, ${ }^{2}$ Thomas S. Herman, ${ }^{1}$ Shawn $\mathrm{O}^{\prime}$ Connell, ${ }^{1}$ \\ Lorin Olson, ${ }^{1}$ BongGun Ju, ${ }^{1}$ Jessica Tollkuhn, ${ }^{1}$ Sung Hee Baek, ${ }^{1}$ David W. Rose, ${ }^{3}$ and \\ Michael G. Rosenfeld ${ }^{1,4}$ \\ ${ }^{1}$ Howard Hughes Medical Institute, School and Department of Medicine, University of California San Diego, La Jolla, \\ California 92093, USA; ${ }^{2}$ Medical Research Council Centre for Developmental Neurobiology, Kings College London, London \\ Bridge, London SE1 1UL, UK; ${ }^{3}$ Department of Medicine, University of California San Diego, La Jolla, California 92093, USA
}

Understanding the functional significance of the coordinate expression of specific corepressors and DNA-binding transcription factors remains a critical question in mammalian development. During the development of the pituitary gland, two highly related paired-like homeodomain factors, a repressor, Hesx1/Rpx and an activator, Prop-1, are expressed in sequential, overlapping temporal patterns. Here we show that while the repressive actions of Hesx1/Rpx may be required for initial pituitary organ commitment, progression beyond the appearance of the first pituitary (POMC) lineage requires both loss of Hesx1 expression and the actions of Prop-1. Although Hesx1 recruits both the Groucho-related corepressor TLE1 and the $\mathrm{N}-\mathrm{CoR} / \mathrm{Sin} 3 / \mathrm{HDAC}$ complex on distinct domains, the repressor functions of Hesx1 in vivo prove to require the specific recruitment of TLE1, which exhibits a spatial and temporal pattern of coexpression during pituitary organogenesis. Furthermore, Hesx1-mediated repression coordinates a negative feedback loop with FGF8/FGF10 signaling in the ventral diencephalon, required to prevent induction of multiple pituitary glands from oral ectoderm. Our data suggest that the opposing actions of two structurally-related DNA-binding paired-like homeodomain transcription factors, binding to similar cognate elements, coordinate pituitary organogenesis by reciprocally repressing and activating target genes in a temporally specific fashion, on the basis of the actions of a critical, coexpressed TLE corepressor.

[Key Words: Pituitary; transcriptional repression; Hesx1/Rpx; Prop-1; TLE1; N-CoR]

Received August 8, 2001; revised version accepted October 9, 2001.

Similar to developmental events in other organ systems, the transcriptional programs coordinating the commitment, patterning, and cell-type determination of the pituitary gland are associated intimately with the activities of localized signaling centers. The pituitary is derived from the midline of the anterior neural ridge (ANR), in which a series of transcription factors that are initially induced in the ANR remain present following the invagination of oral ectoderm to form Rathke's pouch, which will subsequently give rise to the pituitary gland (for review, see Sheng and Westphal 1999; Dasen and Rosenfeld 2001). Following Rathke's pouch formation, signaling events mediated by opposing dorsal FGF/

We dedicate this manuscript to Dr. Rosa Beddington for her many fundamental contributions to developmental biology, which include initial descriptions of Hesx1.

${ }^{4}$ Corresponding author.

Article and publication are at http://www.genesdev.org/cgi/doi/10.1101/ gad.932601.
BMP4 and ventral Shh/BMP2 gradients impart positional and proliferative cues to the initially uniform pituitary progenitor field, acting in part through the induction of combinatorial patterns of transcription factor gene expression.

Genetic and biochemical studies have established the essential roles of multiple transcription factors in pituitary development, which appear to act in a sequential fashion to mediate the appearance of six hormone-producing cell types. These include homeodomain factors expressed in the anterior neural plate, including Pitx1/2, Pax6, and Hesx1/Rpx. Upon the invagination of oral ectoderm, the LIM homeodomain factor Lhx3 is induced on embryonic day (E)9.5 in the nascent Rathke's pouch and is required for initial organ commitment and growth (Sheng et al. 1996). Subsequently, a second paired-like homeodomain factor, Prophet of Pit-1 (Prop-1) appears on E10.5, and is required for determination of four ventral cell types, including the Pit-1-dependent lineages 
(somatotropes, lactotropes, and thyrotropes) and gonadotropes (Sornson et al. 1996; Wu et al. 1998), with additional factors, including Pit-1, SF-1, and GATA-2 also required for cell-type specification within these four lineages (for review, see Dasen and Rosenfeld 2001).

The paired-like homeodomain factors Hesxl/Rpx and Prop-1 are expressed in spatially and temporally distinct and overlapping fashions throughout pituitary development. On the basis of the analysis of Ames dwarf $(d f)$ mice, which bear a hypomorphic mutation in the homeodomain of the Prop-1 gene, and more severe human mutations, Prop-1 is required for the activation of gene programs required for the ventral proliferation and determination of four cell lineages. Hesx 1, in contrast, is typical of developmentally critical transcriptional repressors and plays a broader role in the development of multiple placodally derived anterior structures including the eye, olfactory epithelium, forebrain, and pituitary (Dattani et al. 1998; Martinez-Barbera et al. 2000; Thomas et al. 2001). Attenuation of Hesx1 expression in the developing pituitary coincides with the Prop-1-dependent progression of the pituitary, suggesting that the temporal regulation of Hesx1 expression is essential for deployment of the Prop-1-dependent gene activation program (Gage et al. 1996; Hermesz et al. 1996; Sornson et al. 1996).

The coregulatory apparatus that mediates Hesx1-dependent repression is unknown, although the nuclear receptor corepressor (N-CoR) has been linked to repression mediated by the homeodomain (Laherty et al. 1998; Xu et al. 1998). Another class of corepressors that have been linked to many homeodomain factors are the mammalian orthologs of the Drosophila protein Groucho (for review, see Chen and Courey 2000). Groucho is distantly related to the yeast corepressor Tup1, which binds several components of the core transcriptional apparatus, including Srb7, Srb10, Srb11, and Med6, as well as histone deacetylases (Kuchin and Carlson 1998; Gromoller and Lehming 2000; Watson et al. 2000; Wu et al. 2001). Both Groucho and Tup1 contain WD40 repeats, a wellcharacterized protein-protein interaction domain that has been linked to repression mediated by associations with DNA-binding proteins including transcription factors and histones (for review, see Chen and Courey 2000).

Here, we report that two related paired-like homeodomain factors, a Groucho-dependent repressor, Hesx1, and a transcriptional activator, Prop-1, exert temporally distinct reciprocal functions during pituitary development. Whereas Hesxl-dependent repression in a cell culture model system can involve the actions of either the $\mathrm{N}-\mathrm{CoR} / \mathrm{mSin} 3 / \mathrm{HDAC}(1 / 2)$ and the Brg-1 complexes recruited to the homeodomain, recruitment of the coexpressed Groucho-like TLE1 corepressor by the Hesx $1 \mathrm{~N}$ terminal eh1 domain appears required and sufficient for the repressive actions of Hesxl in vivo. A failure to extinguish expression of Hesx1 and TLE1 after E12.5 phenocopies the pituitary defects in Prop-1-defective mice, leading to pituitary dysmorphogenesis and loss of the Pit-1-dependent and gonadotrope lineages. Intriguingly,
Hesxl can also mediate cell nonautonomous effects on pituitary development by restricting FGF8 and FGF10 expression to discrete boundaries in the ventral diencephalon, without which multiple pituitary glands are ectopically induced in the oral ectoderm.

\section{Results \\ Functional antagonism between Hesx1 and Prop-1 in pituitary organogenesis}

The development of the pituitary gland appears to be coordinated by the sequential actions of a series of transcription factors, two of which, Prop-1 and Hesx1, belong to a family of paired-like homeodomain proteins sharing a conserved DNA-recognition site. The reciprocal expression and actions of Prop-1 and Hesxl suggested that pituitary organogenesis might require their functional interactions. Subsequent to its induction in the anterior neural plate, Hesx 1 expression is maintained in the migrating oral ectoderm and invaginating Rathke's pouch, with selective expression in Rathke's pouch maintained until E13.5, but is excluded from the ventral rostral tip of the pituitary gland (Fig. 1A; data not shown). In contrast, Prop-1 expression is undetectable until between E10.5 and E11, becomes maximal during the ventral migration of pituitary lineage precursors beginning at E12.5, and remains detectable between E14.5 and E15.5, after which its expression is maintained at low levels (Fig. 1A). Prop-1 and Hesx 1 each bind to a well-described palindromic site (PrdQ; Wilson et al. 1993) as cooperative homodimers or heterodimers, with Prop-1 acting as an activator, but not as a repressor (Sornson et al. 1996; data not shown). Hesx1 acts only as a repressor in transient cotransfection assays and can inhibit Prop-1 activation function (Sornson et al. 1996; data not shown). Both the $\mathrm{N}$-terminal and homeodomain (HD) regions of Hesx1 can act independently as repressors of the thymidine kinase (tk) promoter when evaluated as Gal4 fusions (Fig. 1B).

On the basis of the requirement for Hesx1 in the development of anterior organs (Dattani et al. 1998; Martinez-Barbera et al. 2000; Thomas et al. 2001), we investigated defects in pituitary development in Hesx1 genedeleted mice. The most striking, although not frequent ( $5 \%$ of Hes $\times 1^{-/-}$mice), phenotype was characterized by a complete lack of the pituitary gland. In this case, an initial thickening of oral ectoderm and minimal activation of Lhx3 was observed at E12.5, but the pituitary gland was absent by E18.5 (Fig. 1C,D). In these mice, the ventral diencephalon appeared normal and expressed the normal FGF and BMP4 markers. Thus, it became of particular interest to investigate whether earlier expression of the related transcriptional activator, Prop-1, would, presumably by activation of Hesx1-repressed genes, be capable of phenocopying the pituitary arrest observed in Hes $\times 1^{-/-}$mice. Therefore, Prop-1 was targeted in transgenic mice under control of the 8-kb Pitx1 regulatory sequences, which we have shown to be expressed only in oral ectoderm, Rathke's pouch, and first branchial arch 


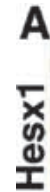

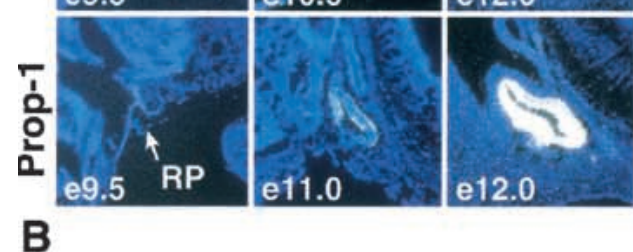

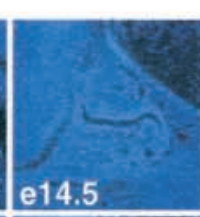

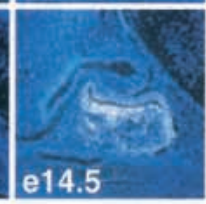

UAS tk/LacZ

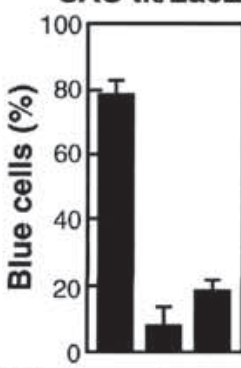

Gal/Hesx1 N' - + Gal/Hesx1 HD - - +

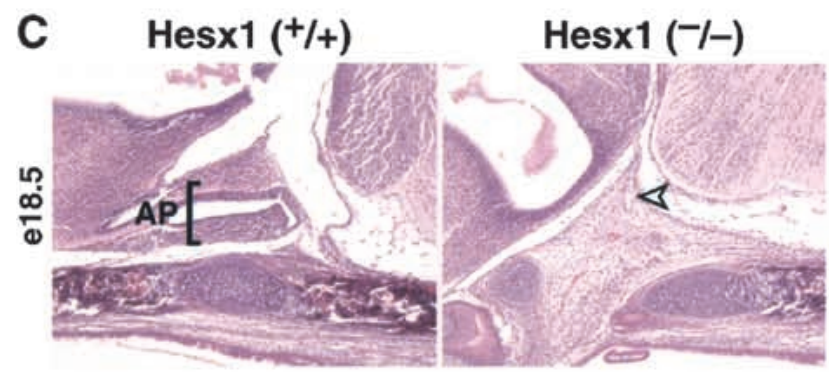

D

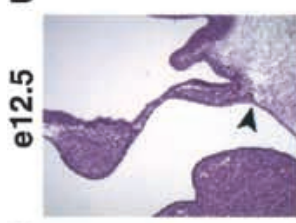

E

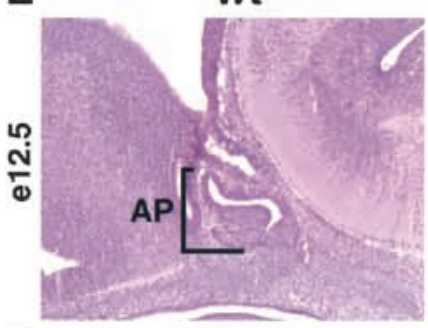

$\mathbf{F}$

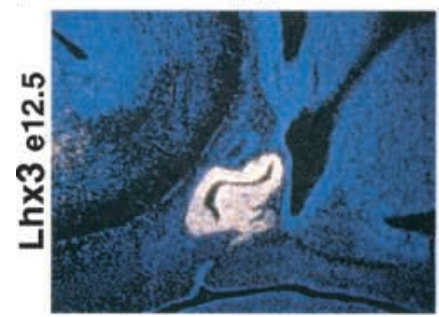

$\operatorname{Hesx1}(-I-)$

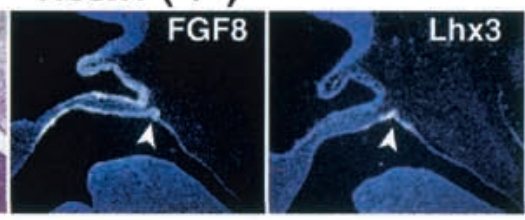

Pitx1/Prop-1

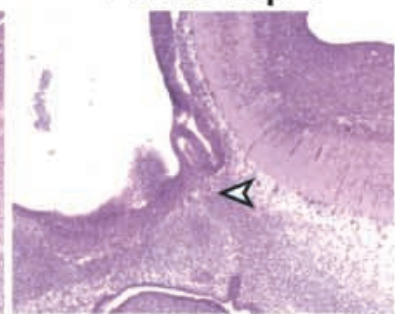

Pitx1/Prop-1

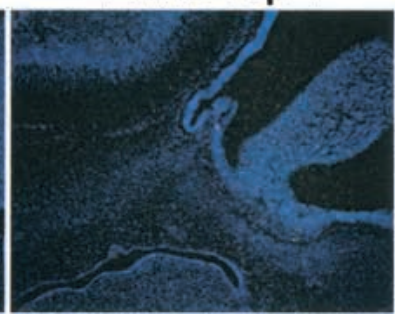

(Treier et al. 1998, 2001). Transgenic founders analyzed between E12.5 and E18.5 were found to exhibit entirely absent anterior pituitary glands, with no abnormalities of developing ventral diencephalon (Fig. 1E). Consistent with a loss of pituitary organ commitment, no initial induction of $L h x 3$ expression was observed in Rathke's pouch at E12.5 (Fig. 1F). Thus, either absence of Hesx1 or the premature presence of Prop-1 serves to block pituitary organogenesis.

\section{Multiple pituitary patterning and growth defects in Hesx1 mutant mice}

In most cases of Hesx 1 gene deletion, pituitary development proceeds beyond formation of Rathke's pouch. In these less severe Hesx1 mutants, the contact of the overlying neural epithelium of the ventral diencephalon with the dorsal part of the pouch proceeds normally from E8.5 to E11.5 (Fig. 2A). However, by E12.5, these mutants were characterized by the formation of multiple oral ectoderm invaginations, apparently reflecting pituitary glands, and were observed in most Hesx 1 embryos analyzed $(n>30)$ (Fig. 2A-C). Between E13.5 and E15.5, during the time in which pituitary lineages are sequentially generated, Hesx 1 mutants were also characterized by a dramatic cellular overproliferation, leading to a failure of the underlying mesenchyme to condense and form the sphenoid cartilage that separates the pituitary from the oral cavity. These two less severe phenotypes - the formation of multiple pouch invaginations and pituitary overproliferation - appeared to occur independently, as we have observed pituitary overgrowth in mice exhibiting a single pituitary invagination and delayed ventral proliferation in animals containing multiple Rathke's pouches (Fig. 2A,D; data not shown).

Figure 1. Opposing roles of Hesx 1 and Prop-1 in initial phases of pituitary organogenesis. (A) Hesx 1 expression is detected in Rathke's pouch at mouse embryonic stage (e) 9.5 and is maintained until E12.5, after which its expression is rapidly extinguished. Prop-1 expression, in contrast, initiates between E10.5 and E11 and is maintained throughout early pituitary development and attenuates beginning at E14.5. (B) The $\mathrm{N}$ terminus $\left(\mathrm{N}^{\prime}\right)$ and homeodomain (HD) of Hesxl act as separable repression domains when evaluated in nuclear microinjection experiments as Gal4 DNA-binding domain fusions on a UAS tk/lacZ reporter. Data represent the average of at least three independent experiments and error bars indicate the standard deviation from the mean. $(C)$ Hematoxylin and eosin staining of midline saggital sections showing that in the most severe class of Hesx1 mutants, the anterior pituitary (AP) gland is absent at E18.5. Rostral is shown at left. (D) Earlier in development, there was a rudimentary pouch formed characterized by minimal $L h \times 3$ activation and ectopic FGF8 expression in the oral ectoderm. $(E)$ Analysis of Pitx1/Prop-1 transgenic embryos showing that ectopic early activation by Prop- 1 phenocopies the loss of pituitary gland in the most severe class of Hesx 1 mutants. Embryonic founder mice analyzed at E12.5 are shown. Arrowheads indicate the region where the pituitary is normally found. No defects in the development of the infundibulum are observed. $(F)$ Pitx1/Prop1 mice also fail to induce Lhx3 expression at E12.5. 

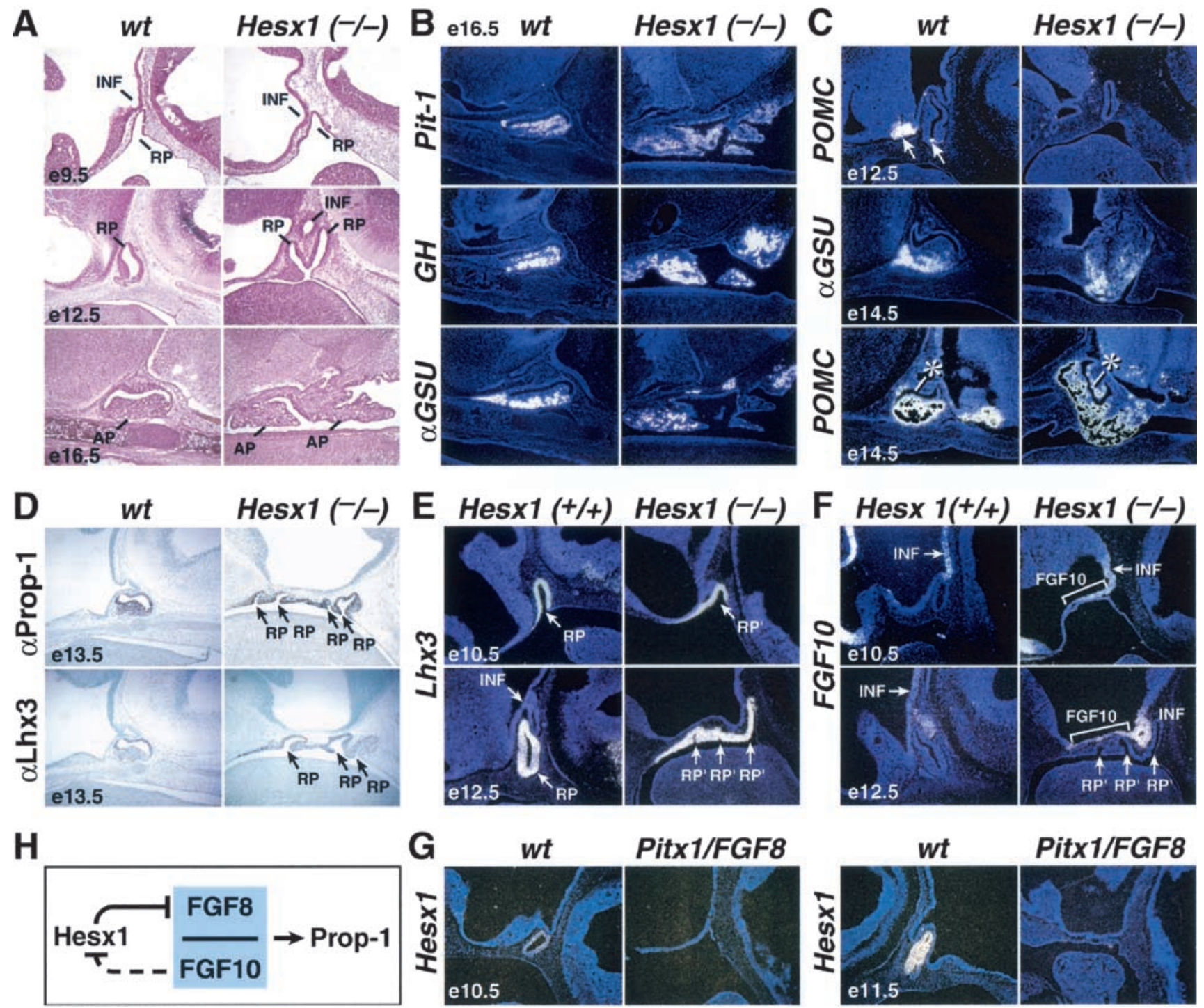

Pitx1/FGF8

Figure 2. Pituitary dysmorphogenesis and patterning defects in other classes of Hesx 1 gene-deleted mice. $(A)$ Hematoxylin and eosin staining of embryonic pituitary glands of Hesx1 gene-deleted mice characterized by normal formation of Rathke's pouch (RP) at E9.5 and dysmorphogenesis beginning at E12.5. These classes of Hesx1 mutant animals were characterized by formation of multiple pouch invaginations (E12.5 shown) or overproliferation of pituitary cells (E16.5 shown) into the sphenoid cartilage region. The morphology of the infundibular recess (INF) overlying Rathke's pouch was normal in these Hesx1 mutants. (B) In situ hybridization showing that terminal differentiation of ventral pituitary cell lineages occurred normally in Hesx1 mutant animals characterized by overproliferation as determined by normal expression of Pit-1, growth hormone (GH, expressed in somatotropes), and alpha glycoprotein subunit $(\alpha G S U$, expressed in presumptive thyrotropes and gonadotropes) at E16.5. The relative proportion of cell types was greatly expanded in these Hesx 1 mutants. Asterisks, overexposed. $(C)$ Expression of proopiomelanocortin (POMC, expressed in corticotropes and melanotropes) and $\alpha G S U$ in Hesx1 mutants showing delayed appearance of POMC lineages at E12.5 and dual induction of $\alpha G S U$ and POMC (arrows) in the rostral and caudal regions of the ventral pituitary. $(D)$ Immunohistochemistry of Hesx1 mutant animals at E13.5, revealing that the additional invaginating oral ectoderm expressed the pituitary markers Prop-1 and Lhx3, indicating that the more rostral regions of oral ectoderm were being induced to form pituitary. (E) In situ hybridization ontogeny of Lhx3 expression showing rostrally extended expression in most Hesx1 mutant animals. $(F)$ The extended expression domain of Lhx3 correlated with extended expression domains in FGF10 within the infundibulum. Similar results were obtained for FGF8. (G) Expression of FGF8 inhibits Hesx1 expression in Pitx1/FGF8 transgenic mice. $(H)$ Model for the reciprocal feedback regulation of FGF and Hesx1 expression.

In the late stages of pituitary development, the terminal differentiation of the hormone-producing cell types appeared normal in most Hesx1 mutants, with expression of $\alpha G S U, T S H \beta, G H, P O M C$, and Pit-1 appearing by E16.5, indicating that cell lineages had differentiated properly (Fig. 2B,C). The onset in the expression of most terminal markers appeared on a normal developmental schedule, but with consistently dramatic increases in numbers. Earlier in development, however, there was a delay in the onset of $P O M C$ expression both within 
Rathke's pouch and the developing hypothalamus at E12.5, and there also appeared to be a dual induction of $\alpha G S U$ expression on both the rostral and caudal sides of Rathke's pouch (Fig. 2C). These data are consistent with Hesxl also playing a general role in the early growth and patterning of the developing pituitary gland.

A negative feedback loop between Hesx1 and FGF8/10 establishes appropriate boundaries for pituitary organogenesis

The formation of multiple pouch invaginations in Hesx 1 mutants (Fig. 2A,D) suggested that additional oral ectoderm might be recruited to form pituitary. Consistent with this observation, analysis of Hesx 1 mutants revealed expanded expression domains of Lhx3 and Prop-1, extending into more anterior regions of the oral ectoderm (Fig. 2D,E). Previous data have suggested pituitary organogenesis is initiated by inductive signaling originating from multiple signaling centers, including dorsal BMP4, FGF8, and FGF10 signals from the infundibular region of the ventral diencephalon, BMP2 from within the pouch and surrounding mesenchyme, and Shh from the ectodermal border between the pouch and oral ectoderm (Ericson et al. 1998, Treier et al. 1998, 2001). On the basis of previous studies showing that $L h x 3$ expression can be regulated by FGF signaling (Ericson et al. 1998; Treier et al. 1998), we investigated potential defects in the expression domains of FGF8 and FGF10 in Hesx 1 mutants bearing multiple pouch invaginations. The expression domains of FGF8 and FGF10 in the infundibulum (Fig. 2F; data not shown), were expanded more rostrally, corresponding to the ectopic expression of $L h x 3$ in the oral ectoderm (Fig. 2E), indicating that Hesx 1 is required for maintaining the proper domains of FGF expression. Furthermore, in the mutants characterized by severe pituitary defects, we observed FGF expression in the oral ectoderm (Fig. 1D), underscoring the requirement for Hesxl function in defining FGF expression boundaries.

Because Hesx1 appears critical for maintaining boundaries of FGF expression and because increased infundibular FGF signaling correlates with Hesx1 down-regulation, we were interested in exploring whether a negative feedback loop between Hesx1 and FGF8/10 expression might exist. Both FGF8 and FGF10 are initially expressed in the most dorsal aspect of the infundibulum, which makes contact with the dorsal tip of Rathke's pouch at E9.5. Between E12.5 and E14.5, as Hesx1 expression attenuates, the domain of FGF expression begins to extend ventrally as the infundibulum makes contact with the dorsal wall of the pouch (Ericson et al. 1998; Treier et al. 1998). To investigate whether misexpression of a FGF would negatively regulate Hesx 1 expression earlier in development, we generated mice expressing FGF8 under the control of the Pitx 1 regulatory sequences. In these mice, which express FGF8 in oral ectoderm /data not shown), Hesx1 expression was completely absent in embryonic founders analyzed at E10.5 and E11.5 (Fig. 2G).
Thus, Hesx1 and FGF appear to exert reciprocal feedback regulation during pituitary development (Fig. $2 \mathrm{H}$ ).

\section{Hesx1 recruits the Groucho-related corepressor TLE1}

The phenotypes of Hesx 1 mutants - the complete absence of the pituitary gland, the failure to restrict FGF8/ 10 out of the rostral ventral diencephalon, and pituitary overgrowth - are consistent with Hesxl acting in vivo as a transcriptional repressor. Attempts to delineate specific domains of Hesx1 required for transcription repression, provided that, under conditions of limiting plasmid concentrations, separation of the $\mathrm{N}$ terminus and homeodomain regions led to attenuated repression capacity, suggesting the presence of separable and cooperative repression domains (Fig. 1B). Comparison of Hesx1 sequences from several vertebrate species revealed the presence of two conserved motifs outside of the homeodomain, one of which showed similarity to the eh1 motif originally characterized in the Drosophila repressor engrailed (Smith and Jaynes 1996), whereas a second conserved motif showed similarity to the WRPW motif found in several bHLH proteins (Paroush et al. 1994). Because both of these motifs have been genetically and biochemically linked to the Groucho class of corepressors (Jimenez et al. 1997; Tolkunova et al. 1998), we determined whether TLE factors, mammalian counterparts of Groucho, mediate repression through the Hesx1 N terminus. We first investigated a physical association between Hesx 1 and TLE proteins by combining HeLa cell nuclear extracts with Hesxl affinity resin, finding a strong and specific interaction with TLE corepressors (Fig. 3A).

We performed in situ hybridization to analyze expression of the four mammalian Groucho homologs, TLE1TLE4 (Stifani et al. 1992) between E9 and E16 of development, and found that expression of TLE1 selectively overlaps with Hesx1 during pituitary ontogeny (Fig. 3B). Thus, Hesx 1 and TLE1 are coexpressed within Rathke's pouch between E9.5 and E12, but become rapidly extinguished beginning at E13.5, the time at which nascent anterior lobe pituitary cell types appear from Rathke's pouch. On the basis of the overlapping expression patterns of TLE1 and Hesx1 during pituitary ontogeny, we focused on TLE1 as the mediator of repression by the Hesx1 $\mathrm{N}$ terminus.

Coexpression of TLE1 and Hesx1 in heterologous 293T cells and immunoprecipitation against Hesx 1 indicates a robust physical interaction in vivo (Fig. 3C). Furthermore, this interaction proved to be specific, as we did not detect interactions with other pituitary-restricted factors such as Pit-1, Prop-1, and GATA-2, or surprisingly, the eh1 domain-containing homeodomain repressor, Msx1 (Fig. 3D), for reasons that are not clear. In transfectionbased assays, TLE1 supported transcriptional repression of the tk promoter by Hesxl on the cognate PrdQ-binding site (Fig. 3E). Whereas Hesx1 alone could only partially abrogate the activity of Prop-1 on the PrdQ site, the presence of TLE1 completely abolished transcriptional activation mediated by Prop-1 (Fig. 3E). Furthermore, on 

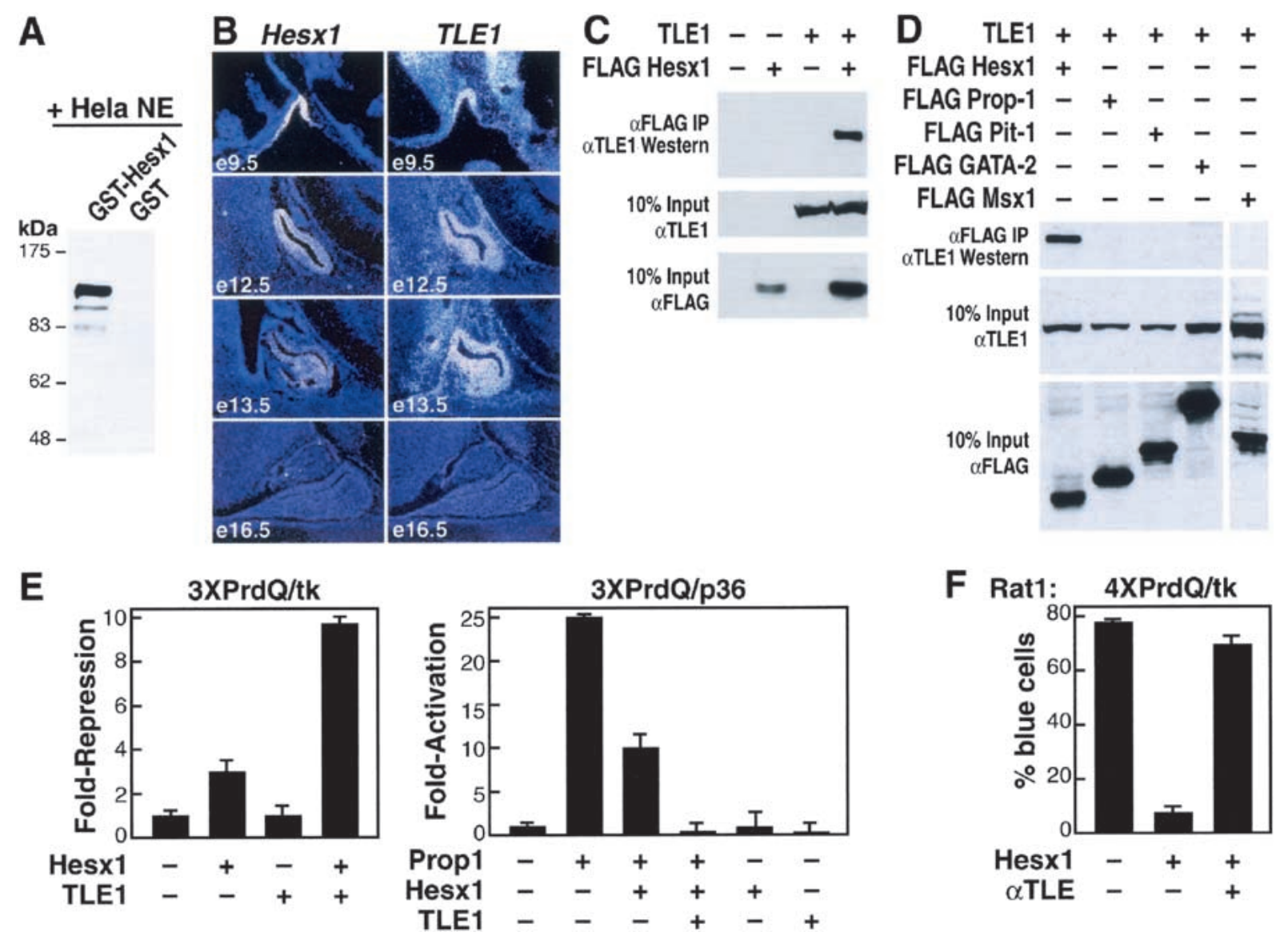

Figure 3. Expression and physical interactions of TLE1 and Hesxl during pituitary development. (A) Hesx1 binds TLE family corepressors. GST-precleared HeLa nuclear extracts $(750 \mu \mathrm{g})$ were combined with a full-length GST/Hesx1 fusion protein and tested for the presence of TLE using a pan-TLE antibody. (B) In situ hybridizations showing expression of TLE1 overlaps with Hesx1 during pituitary early ontogeny and is attenuated by E16.5. (C) Specific interactions between Hesxl and TLE1 mediate transcriptional repression. FLAG epitope-tagged CMV-Hesx1 and CMV-TLE1 were expressed in 293T cells and coimmunoprecipitation was performed using anti-FLAG antibody. The presence of TLE1 was tested by use of a rabbit polyclonal TLE1 antibody. (D) No interactions with TLE1 were detected after immunoprecipitation with FLAG-tagged Prop-1, Pit-1, GATA2, or Msx1. (E) TLE1 mediates repression by Hesx1 and inhibition of Prop-1 function. TLE1-pcDNA3 (50 ng) supported repression by Hesx1-pCMX (50 ng) on the 4XPrdQ/tk reporter and also abolished Prop-1-dependent transcriptional activation of the 3XPrdQ/p36 reporter. $(F)$ Nuclear microinjection in Rat1 cells showing the antibodies direct against TLEs can block repression mediated by Hesx1 on a 4XPrdQ/tk reporter.

the PrdQ/tk promoter, microinjection of $\alpha$ TLE IgG blocked repression mediated by Hesxl (Fig. 3F). Together, these data suggest that Hesxl can recruit TLE1 to specific promoters, leading to direct transcriptional repression as well as inhibition of the activity of other paired-like heterodimeric partners such as Prop-1.

\section{An evolutionarily conserved interaction mediates TLE1-dependent repression by Hesx1}

We further explored the mechanisms of TLE-dependent repression, focusing specifically on the mechanism by which TLE1 supported repression of Hesxl and abrogated transcriptional activation mediated by Prop-1. Because recruitment of Groucho-class corepressors can be mediated through both the eh1 and WRPW motifs, we investigated the Hesxl interaction domain. Using bacte- rially expressed domains of Hesxl, we mapped the interaction interface to its $\mathrm{N}$ terminus, a region containing both of these motifs (Fig. 4A,B). Generation of point mutations within the two conserved motifs revealed the specific requirement for the eh1 domain for the Hesx1/ TLE1 interaction in vivo (Fig. 4C). By generating fusions of Hesxl fragments to the heterologous Gal4 DNA-binding, TLE-dependent repression of a UAS/tk promoter proved to be mediated through the $\mathrm{N}$ terminus of Hesx 1 , not the homeodomain (Fig. 4D). Furthermore, mutation in the eh1 domain, but not the second conserved motif, abrogated TLE1-mediated repression by the $\mathrm{N}$ terminus as well as repression by Gal4/holo-Hesx1 (Fig. 4E,F). Together, these data show that TLE1-dependent repression by Hesxl is supported by a specific interaction with the eh1 domain.

We mapped the physical interaction on TLE1 in vivo and found that both the $\mathrm{N}$-terminal tetramerization $/ \mathrm{Q}$ 

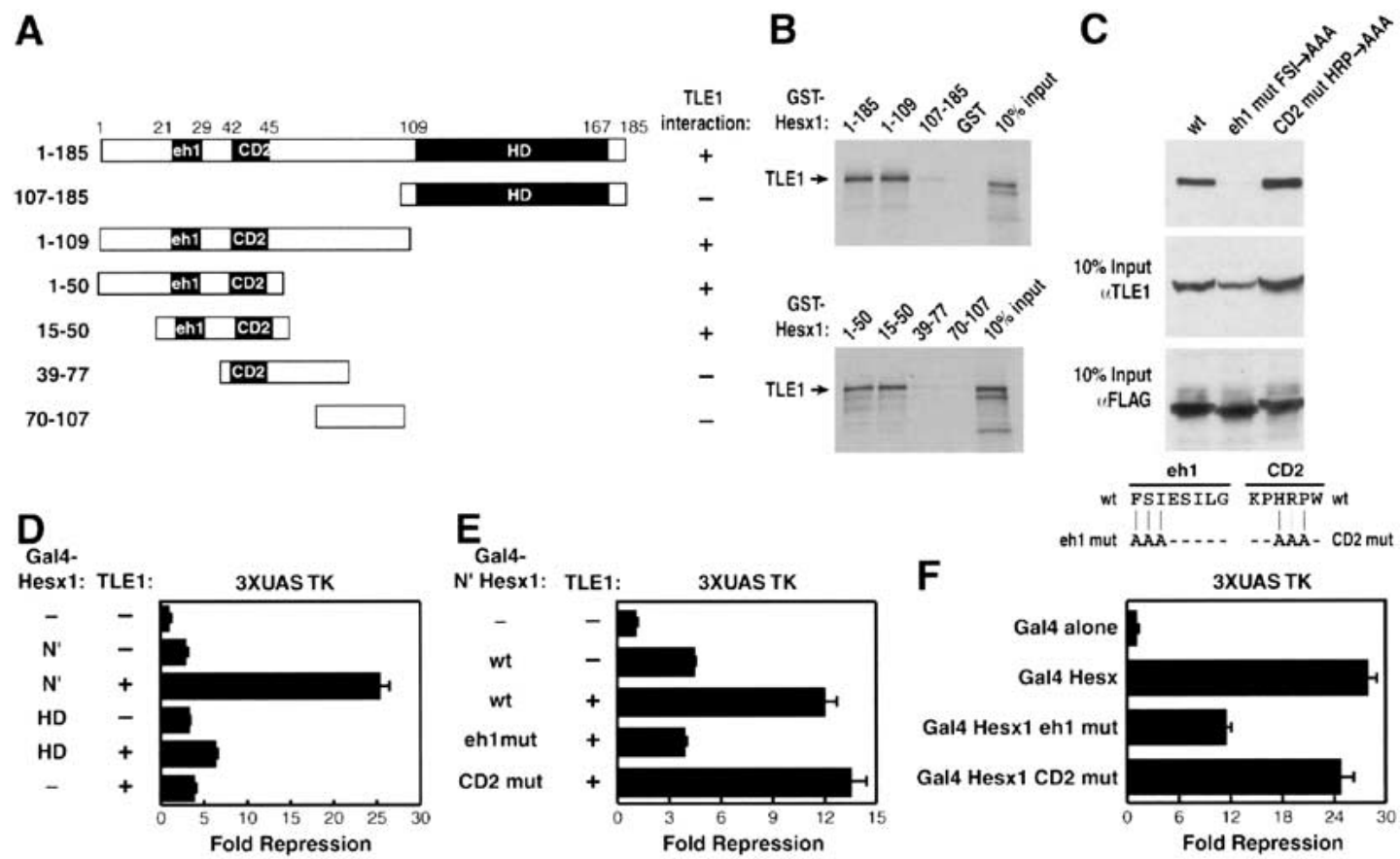

$\mathbf{E}_{\text {Gal4 }}$

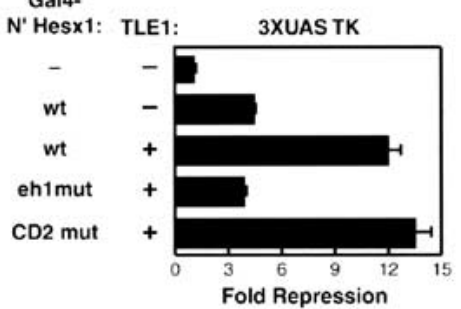

F

eh1 mut AAA-.....--AAA- CD2 mut

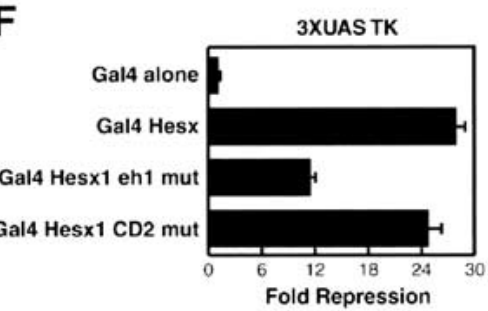

G
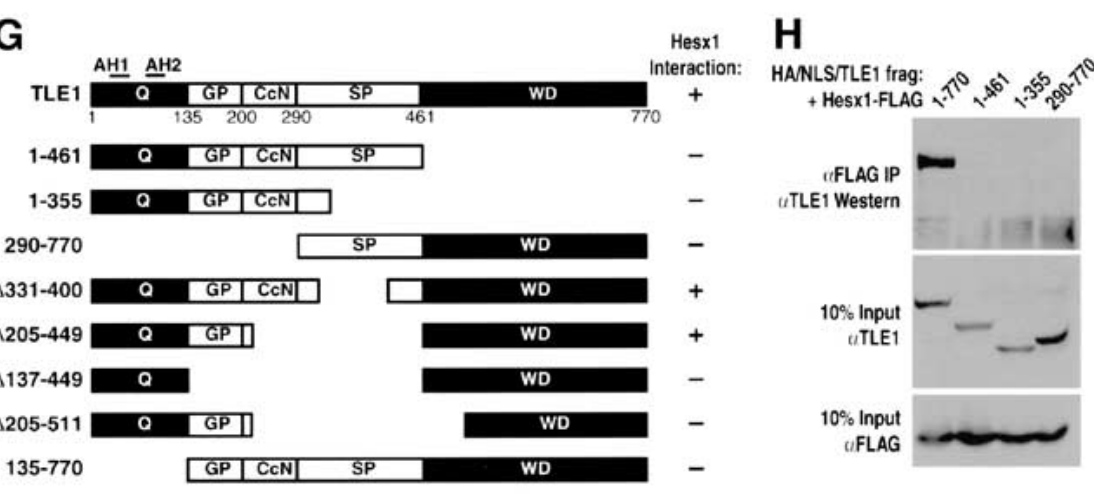

I
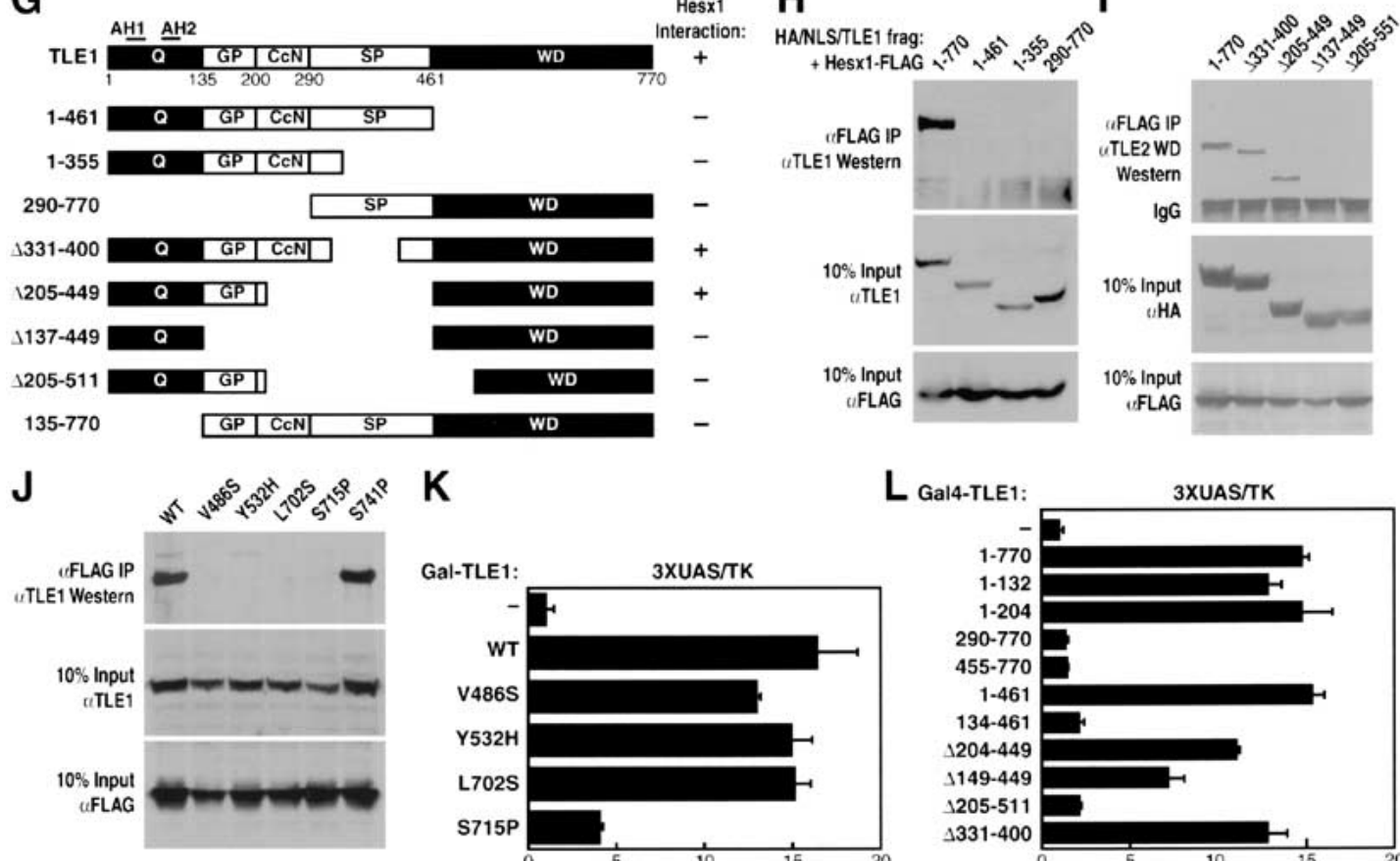

K

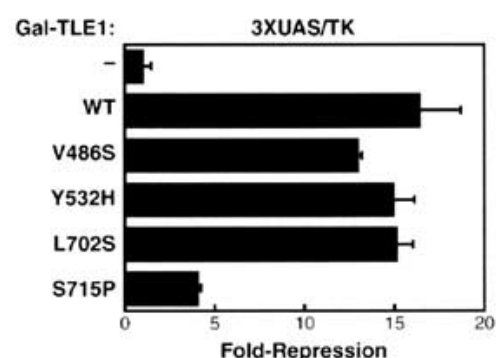

L Gal4-TLE1:

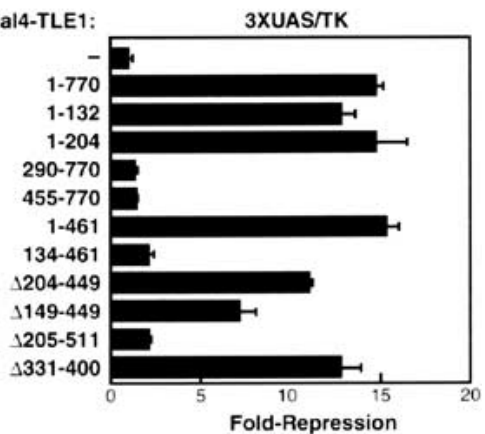

Figure 4. Conserved functions of eh1 domain/WD40 domain interactions in mediating transcriptional repression. $(A)$ Schematic representations of Hesx 1 fragments expressed as GST-fusion proteins. $(B)^{35}$ S-labeled full-length TLE1 was combined with bacterially expressed GST-fusions of Hesxl and analyzed for interaction after SDS-PAGE and film exposure. TLE1 bound to an N-terminal region containing the conserved N-terminal amino acid residues. (C) Point mutation in the eh1 domain but not the second conserved domain (CD2) of Hesxl were tested for TLE1 interaction by immunoprecipitation and revealed a specific requirement for the eh1 domain. (D) Repression by TLE1 is mediated through the Hesx1 N terminus. Gal4 fusions of Hesxl domains were tested for repression on a 3XUAS/tk luciferase reporter in the presence or absence of TLE1. (E-F). Mutation in the eh1 domain of Hesx1 abrogated repression by TLE1 by both the $\mathrm{N}$ terminus and repression of full-length Hesx1-Gal4 fusion. (G) Schematic representations of TLE1 domains. (H-I) Coexpression of FLAG-Hesx1 and TLE1 subdomain expressed as HA tagged/nuclear localization signal (NLS) fusion proteins were tested for interaction by coimmunoprecipitation assays. (Right) An antibody directed against the conserved WD40 domain of TLE2 was used. (J) Point mutations in the WD40-repeat region of TLE1 revealed that residues conserved in Tup1 are required for Hesx1 interaction. $(K)$ Nonstructural point mutations in TLE1 had no effect on the ability of Gal-TLE1 to repress. $(L)$ Gal4 fusions of TLE1 subdomains revealed a requirement for the GP and WD40 domain in transcriptional repression. 
and GP) domain and WD-repeat region were required for the interaction (Fig. 4G-I). On the basis of analogy to interactions between Tup 1 and the MAT $\alpha 2$ homeodomain, we focused on the analysis of the WD40 region as potentially forming the interaction surface. We generated point mutations in the WD40 domain within conserved or analogous residues between TLE1 and Tup1, which, in Tup1, have been shown to be required for the interaction of the MAT $\alpha$ terminal peptide and the channel surface formed by the propeller blades of the WD40 domain (Sprague et al. 2000). Mutation in four of the five mutated residues tested in these assays abolished Hesx1/ TLE1 interactions (Fig. 4J). Three mutations (V486S, $\mathrm{Y} 532 \mathrm{H}$, and L702S) are predicted to maintain the overall structural integrity of the WD40 repeat, whereas the S715P mutation is predicted to disrupt the overall structure (Komachi et al. 1997; Sprague et al. 2000).

To determine which domains in TLE1 were required for transcriptional repression, we generated Gal4 fusions of the WD40 point mutations as well as subdomains of TLE1. Fusions of the nonstructural point mutations in the WD40 repeat had no effect on the ability of TLE1 to repress a UAS/tk reporter, whereas the structural S715P mutation consistently attenuated TLE1-mediated repression (Fig. 4K). The Q tetramerization domain was sufficient for repression, likely due to recruitment of endogenous TLE proteins (Chen et al. 1998; Ren et al. 1999). Gal4 fusions of TLE1 subdomains demonstrated that, within the context of the TLE tetramerization motif, full transcriptional repression required the GP and WD40 domains (Fig. 4L). Thus, as in the case Tup1, the repression and interaction domains appear to be separable, although the WD40 repeat appears to be required for aspects of both functions.

\section{Regulation of Hesx1 by distinct corepressor complexes}

On the basis of our previous observations that many homeodomain proteins, including Hesxl, require $\mathrm{N}-\mathrm{CoR}$ and associated corepressors for transcriptional repression (Xu et al. 1998), we explored a potential interface between the N-CoR complex and the Groucho class of corepressors. We initially investigated whether $\mathrm{N}-\mathrm{CoR}$ might, at least under certain cellular conditions, be required for Hesx1-mediated repression in vivo. In quiescent Rat-1 cells, both N-CoR and TLE1 were required for repression by Gal4/Hesx1, as microinjection of antibodies against at either factor significantly relieved repression of a UAS/tk reporter (Fig. 5A).

Both N-CoR and Groucho have been reported to bind class I histone deacetylases (HDACs), but because Groucho has been shown to bind the HDAC dRpd3 through its GP domain (Chen et al. 1999), an interaction domain poorly conserved in vertebrate TLEs, and because we were unable to find detectable HDAC/TLE interactions (data not shown), we investigated the possibility that any HDAC interaction with Hesxl might involve indirect recruitment. HeLa nuclear extracts were combined with Hesxl affinity resin consisting of either the $\mathrm{N}$ terminus, homeodomain, or full-length protein, and following washing and elution, tested for the presence of components of known repressor complexes. As expected, we found that the $\mathrm{N}$ terminus was effective in recruitment of TLE corepressors in HeLa cells (Fig. 5B). The Hesx 1 homeodomain was required and sufficient to recruit components of $\mathrm{N}-\mathrm{CoR}$ associated corepressors, including Sin3A/B and HDAC1 and HDAC2, but did not interact with TLE proteins (Fig. 5B). Although the homeodomain was sufficient to mediate N-CoR/HDAC interactions, the presence of the $\mathrm{N}$ terminus significantly enhanced binding of N-CoR and HDAC1, and to a lesser extent, Sin3A/B (Fig. 5B). Furthermore, we also found that whereas Mi2, MTA1, and HDAC3-HDAC6 were not recruited, components of the mammalian SWI/ SNF complex (Brg1) and RbAp46, were found in the homeodomain-purified fraction (Fig. 5B). Consistent with these data, the eluates from the Hesxl homeodomain column contained TSA-sensitive HDAC activity (data not shown).

On the basis of these data, we wished to evaluate the functional importance of these components in actions of the Hesx $1 N^{\prime}$ and HD repression domains. Repression by the N-terminal domain of Hesxl was not inhibited by $\alpha$ HDAC1-HDAC6, $\alpha$ Mi2, $\alpha \operatorname{Sin} 3, \quad \alpha$ Brg1, $\alpha$ BAF57, $\alpha$ BAF55, or $\alpha$ BAF110 IgGs, but was inhibited by $\alpha$ TLE- 1 IgG, indicating that it alone could serve as a component required for Hesx1-dependent repression (Fig. 5C; data not shown). To further evaluate this issue, we examined repression by the Hesx1 holoprotein, or the Hesxl eh1 mutant form that is incapable of interacting with TLEs. With wild-type protein, TLE was required for repression, whereas HDAC1-HDAC6, N-CoR, Brg1, and BAF activities were not required (Fig. 5D). In contrast, in the absence of the TLE interaction domain (Hesxl eh1 mu$\tan t)$, repression was still achieved, but now required the actions of HDAC2, HDAC5, and Brg-1, as well as BAF57, BAF155, and BAF110 (Fig. 5E; data not shown). On the basis of these data, we conclude that, whereas the TLEdependent complex may recruit substoichiometric amounts of deacetylases, HDAC1-HDAC6 are not required for TLE-mediated repression. In contrast, repression can be mediated by the Hesxl homeodomain, requiring both specific HDACs and the actions of the Brgl complex.

Attenuation of Hesx 1 and TLE1 is required for Prop-1-dependent specification of four pituitary cell lineages

The recruitment of $\mathrm{N}-\mathrm{CoR}, \operatorname{Sin} 3 \mathrm{~A} / \mathrm{B}, \mathrm{HDAC} 1$, and HDAC2, as well as TLE to Hesx1 raised the question of whether either complex is critical for the biological functions of Hesxl within the pituitary. The ability of Hesx1/TLE1 interactions to inhibit the activity of Prop1 , and the requirement for Prop- 1 in the determination of four anterior pituitary cell types, initially suggested that the spatially and temporally restricted coexpression patterns of Hesx 1 and TLE1 expression might be a critical component of normal pituitary organogenesis. In an at- 

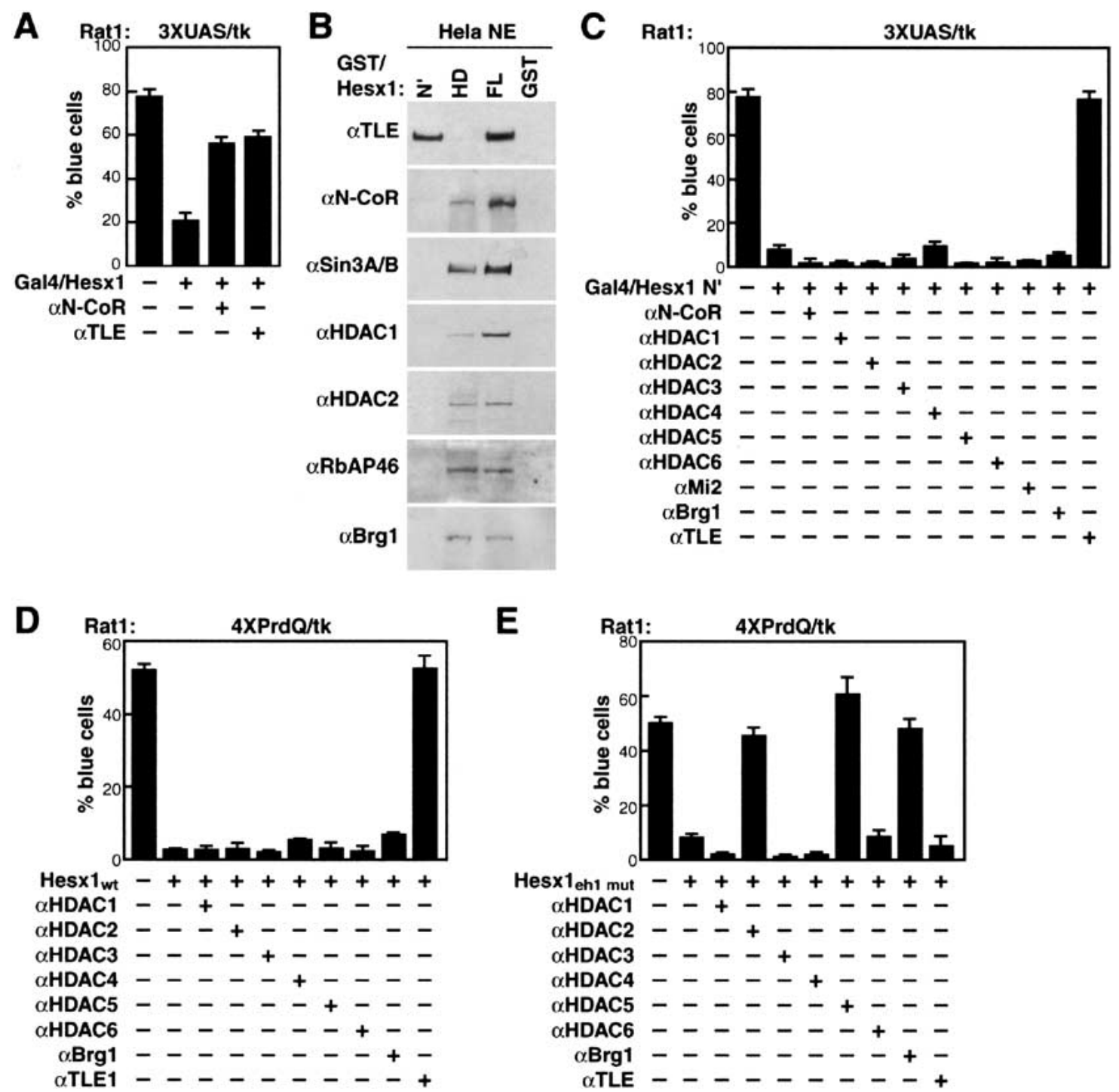

Figure 5. Cooperative interactions of TLE1 and N-CoR and recruitment of Brg1 mediate repression by Hesx1. (A) In Rat 1 cells, on a UAS/tk promoter using Gal4/Hesxl, both N-CoR and TLE1 are required components of Hesx1-mediated repression. Antibodies against TLE1 and N-CoR were microinjected into the nuclei of Rat-1 cells and tested for the ability of Gal4/Hesx1 to repress a UAS/tk lacZ reporter. $(B)$ Coordinate recruitment of distinct corepressor proteins by the Hesx 1 homeodomain and $\mathrm{N}^{\prime}$ terminus. Affinity chromatography using Hesx1 $\mathrm{N}^{\prime}$, homeodomain, or holoprotein was performed with HeLa nuclear extract; after washing and elution, equivalent aliquots were fractionated by SDS-PAGE and used for Western blot analysis. (C) TLE is required for repression by Gal4/ Hesx $1 \mathrm{~N}^{\prime}$ on a UAS/tk reporter. $(D)$ TLE is required for repression by the Hesx1 wild-type protein on a $4 \times$ response element-dependent reporter. $(E)$ Repression by the Hesx1 eh1 mutant on the identical reporter was TLE independent, but was blocked by $\alpha B r g 1, \alpha H D A C 2$, and $\alpha$ HDAC5. In single-cell nuclear microinjection experiments, $\sim 300$ cells were injected for each point; $M \pm S E M$; results were repeated in these independent experiments.

tempt to address the functional significance of TLE1 and Hesx 1 actions in pituitary development, we generated transgenic mice expressing Hesx 1 under the control of regulatory sequences the Pitx1 gene, which would target misexpression to all ventral pituitary cell types, or the $\alpha G S U$ gene, which would maintain Hesx 1 expression in specific cell lineages through later stages of development. In these transgenic animals we observed only minimal phenotypes characterized by a modest reduction in some cell lineages (Fig. 6A,B). In light of the temporally restricted patterns of TLE1 expression, we next evaluated the effects of TLE1 expression alone, finding all cell types present (data not shown).

On the basis of these results, we next addressed whether maintained coexpression of both TLE1 and Hesx1 would be sufficient to inhibit the Prop-1-dependent determination program. We therefore generated transgenic animals, temporally maintaining expression of both Hesx1 and TLE1 under control of regulatory sequences of the Pitx1 gene, which targets expression in the oral ectoderm, and then to progenitor cell types in developing Rathke's pouch. These DNAs were coin- 


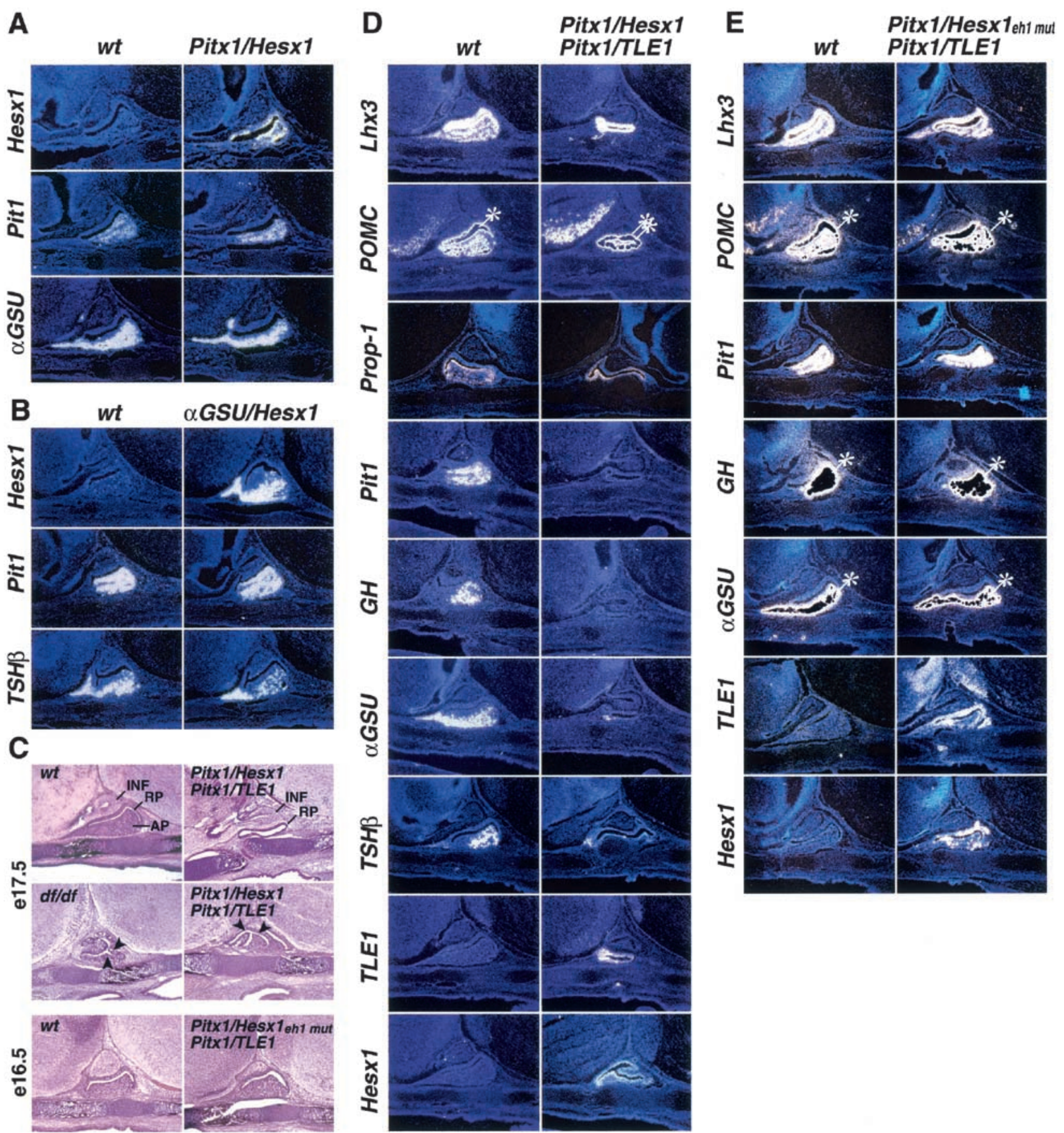

Figure 6. Temporal misexpression of Hesx1 and TLE1 abrogates the Prop-1-dependent ventral proliferation and determination of four pituitary cell types. $(A, B)$ Expression of Hesx1 under the control of regulatory sequences of the Pitx1 and $\alpha G S U$ genes has no adverse effects on the appearance of pituitary cell types analyzed in E16.5 founder animals. $(C)$ Hematoxylin and eosin staining showing the loss of ventral pituitary cell types of Pitx1/Hesx1:Pitx1/TLE1 double-transgenic embryonic founders and similarity to pituitary defects in Ames $d f / d f$ mice. $(D)$ In situ hybridization analysis of Pitx1/Hesx1:Pitx1/TLE1 double-transgenic founder mice at E16.5 showing loss of GH, Pit-1, Prop-1, $\alpha G S U$, and TSH $\beta$ expression, although expression of POMC appears to be unaffected near the lumen of Rathke's pouch. Lhx3 continues to be expressed in the pouch ectoderm, whereas expression of Prop-1 and FGF10 were unaffected (data not shown). (E) Mutation in the eh1 domain of Hesx1 reverts the phenotypes of TLE1 coexpression as determined by normal expression of pituitary markers in Pitx1/Hesx $1^{\text {eh1 mut } / P i t x 1 / T L E 1 ~ t r a n s g e n i c ~ m i c e . ~}$ 
jected into embryos and allowed to concatermerize in vivo. Pitx1/Hesx1:Pitx1/TLE1 double-transgenic embryos were characterized by the near-complete absence of all ventral anterior pituitary cell types (Fig. 6C,D). Rathke's pouch appeared to have formed normally in these animals and continued to express early determination markers such as $L h x 3$ (Fig. 6D). In some transgenic animals $(-30 \%)$, a dysmorphogenesis of Rathke's pouch was observed, characterized by bifurcation of Rathke's pouch ectoderm and dysmorphogenesis, remarkably similar to the pituitary dysmorphogenesis (Gage et al. 1996; Sornson et al. 1996) of Prop-1-defective Ames dwarf mice (Fig. 6C).

Analysis of the expression of pituitary cell type markers in Pitx1/Hesx1:Pitx1/TLE1 mice revealed the complete absence of Prop-1-dependent cell lineages as determined by loss of expression of the Pit-1, GH, TSH $\alpha G S U$ genes (Fig. 6D). Expression of Prop-1 in the pituitary and FGF10 in the ventral diencephalon was unaffected, consistent with this phenotype occurring as a result of the cell-autonomous inhibition of Prop-1 activation function (Fig. 6D; data not shown). Expression of $P O M C$, a marker for the Prop-1-independent melanotrope lineage, as well as the corticotrope lineage, appeared normal in the dorsal, melanotrope cell field. Remarkably, the ventral aspect of Rathke's pouch now expressed a uniform field of $P O M C$ in a manner similar to that in the intermediate lobe of the pituitary gland.

To further test whether the effects of maintained TLE1 and Hesx 1 expression on pituitary development required a specific interaction between these proteins, we generated a mutation in the eh1 domain that abolished TLE1 interaction within the context of the Pitx1/Hesx1 transgene and then coinjected it with the Pitx1/TLE1 expression cassette. These animals robustly expressed both transgenes, but exhibited no defects in the appearance of pituitary cell types nor altered expression of pituitary determination markers (Fig. 6E). This is consistent with the requirement of specific interactions between TLE1 and Hesx 1 as the critical repressor complex serving to prevent the appearance of the Pit-1 and gonadotrope lineages.

\section{Discussion}

The sequential actions of transcriptional repressors and activators on overlapping sets of gene targets, in concert with requisite coregulatory machinery, is likely to be a central strategy in mammalian organogenesis. Here, we explored the opposing roles of two highly-related pairedlike homeodomain factors, Hesx1/Rpx and Prop-1, that exhibit temporally distinct, but overlapping patterns of expression over the entire period of pituitary organ commitment, patterning, and cell-type determination. Our data suggest that Hesx1, although clearly modified by the actions of linked modifier genes on the basis of genetic background, is required for early organ commitment and cell determination events. These actions extend temporally to include the appearance of the dorsal POMC lineage, which then, with a specific coexpressed corepressor, Hesx1, serves to prevent Prop-1 from initiating the program required for asymmetric division and proliferation of the Pit-1 and gonadotrope lineages (Fig. 7). Premature expression of Prop-1 can block pituitary organogenesis, phenocopying the effects of Hesx1-gene deletion, suggesting that the switch of binding of a paired-homeodomain repressor for a paired-homeodomain activator, with resultant alteration in the expression of key target genes, now prevents organogenesis. Conversely, expression of Hesx1 with the obligate corepressor TLE1 can block the activation of Prop-1-dependent genes required for the appearance of four anterior pituitary cell types. This provides a striking example of a potent strategy in mammalian organogenesis, in which opposing actions of related repressors and activators, putatively binding to overlapping sets of gene targets, provide critical temporal control of organ development. Interestingly, later persistent expression of Prop-1 under control of the $\alpha$ GSU promoter caused decreased gonadotrope differentiation and caused increased adenomatous hyperplasia (Cushman et al. 2001).

\section{A Hesx1/FGF regulatory loop in boundary formation}

In addition to its early and later roles in pituitary organogenesis and cell type determination, analysis of Hes $\times 1^{-/-}$ mice have also revealed an intriguing regulatory loop. Early in development, Hesx 1 is expressed in a broad region of the anterior neural plate that will later give rise to the ventral diencephalon and pituitary. Deletion of the Hesx1 gene causes a rostral extension of FGF8 and FGF10 expression in the ventral diencephalon, into an area that transiently expresses Hesx1, leading to ectopic Lhx3 induction and formation of supernumerary pituitary glands, confirming that FGF8/FGF10 signaling is required and sufficient to signal pituitary commitment from oral ectoderm (Treier et al. 2001). Further, our data showing that FGF8 suppresses Hesx1 gene expression indicates a negative regulatory loop with Hesx1 acting early to repress FGF8/FGF10, which in turn, directly or indirectly, represses Hesx 1 gene expression at the time of the emergence of pituitary cell types from Rathke's pouch. Thus, a paired-like homeodomain repressor serves to establish boundaries of FGF8/10 gene expression in the ventral diencephalon and thus restricts the spatial domains at which pituitary organogenesis can occur.

Together, our data suggest that Hesxl can exert both cell-autonomous and noncell-autonomous roles in pituitary development. Early in development, Hesx1 is required for restricting and maintaining the proper expression domains FGF8 and FGF10, consistent with its putative role as a repressor in the anterior neural plate, which establishes boundaries of morphogen expression. Later in development, after its expression becomes restricted to Rathke's pouch between E9 and E12, Hesx1 is required for regulating the appropriate ventral proliferation patterns of pituitary progenitor lineages. These observations are based on the analysis of Hesx 1 mutants, in which the pituitary did not exhibit defects in the ventral 
Dasen et al.

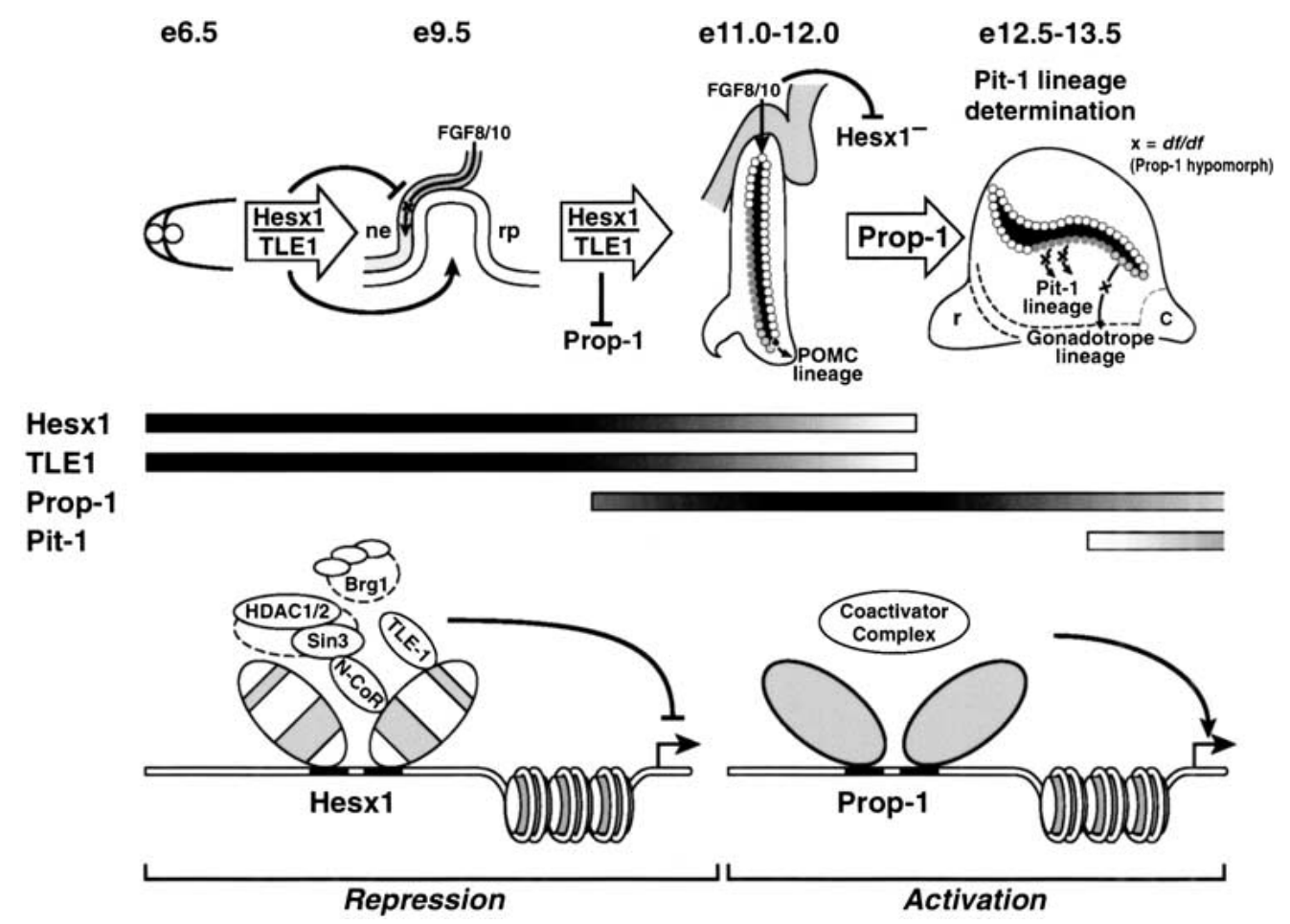

Figure 7. Model for the temporal switch of a homeodomain repressor for an activator, mediated by the coordinate recruitment of distinct corepressor complexes in pituitary organogenesis. In the anterior neural plate, Hesx1 is required for restricting the domain of FGF8 and FGF10 expression to distinct regions of the ventral diencephalon and is later required for the inhibition of Prop-1 function to temporally control the proliferation and determination of four pituitary cell lineages. Conversely, FGF signaling down-regulates Hesx1 expression, necessary for the deployment of the Prop-1 gene program. Hesxl requires the recruitment of coordinately expressed TLE1, but also recruitment of N-CoR, and Brgl complexes, to inhibit in vivo activation events mediated by Prop- 1 .

diencephalon, but continued to proliferate, and are further supported by the in vivo effects of maintained TLE1 and Hesx 1 expression.

\section{TLE1-mediated recruitment of repressor function to Hesx1 in pituitary development}

We have provided evidence in vivo that Hesx 1 contains two repressor domains, located in the $\mathrm{N}$-terminal and homeodomain regions of the protein, each recruiting a distinct corepressor complex. The component recruited by the $\mathrm{N}$ terminus includes one mammalian Groucho ortholog, TLE1, that appears to be required for Hesx1dependent repression, both in cell culture models, in which anti-TLE IgG blocks Hesxl repression activity, and in vivo, in which coexpression of both Hesx1 and TLE1 are sufficient to phenocopy the effects of Prop-1 gene deletion. The strong association between TLE1 and Hesxl is mediated by a highly conserved helical motif (FXLXXIL), which is present in the Hesx1 $\mathrm{N}$ terminus and selectively recruited by purification from the nuclear extracts, as well as by coimmunoprecipitation assay in cells, analogous to interactions of Nkx, Six, and certain Pax homeodomain factors with other TLE family members (Eberhard et al. 2000; Muhr et al. 2001). The inability of the eh-1 domain-containing repressor Msx-1 to bind TLE1 suggests specificity codes between homeodomain repressors and specific TLE corepressors may exist.

In the case of Hesxl, our data suggest that the N-CoR/ Sin3/HDAC(1/2) complex can also be recruited to the Hesx1 homeodomain. However, the component required for effective repression function appears to be dependent on cellular and promoter context. The homeodomain region is alone capable of mediating repression, requiring a corepressor complex that includes $\mathrm{mSin} 3 \mathrm{~A} / \mathrm{B}, \mathrm{HDACl}$, and HDAC2, suggesting recruitment of the $\mathrm{mSin} 3 \mathrm{com}-$ plex, but not of the high-affinity N-CoR/TBL1/HDAC3 complex (Guenther et al. 2000; Underhill et al. 2000) to the Hesx 1 homeodomain. Intriguingly, the Hesx $1 \mathrm{~N}$-terminal domain-binding TLE permits cooperative binding of N-CoR, HDAC1, and Sin3A/B to the homeodomain, a strategy that might be quite common with respect to many homeodomain repressors, and could provide a linkage between one class of corepressors - the TLEs and the $\mathrm{N}-\mathrm{CoR} / \mathrm{mSin} 3$ complexes in the actions of a strong homeodomain repressor.

The molecular basis of actions of the mammalian TLE orthologs of Tup1 and Groucho are still not fully clarified. In yeast, the Tup1/SSN6 complex has been suggested to contact components of core machinery including Srb7, Srb10, Srb11, and Med6. However, we did not 
find comparable direct associations between TLE1 and the mammalian counterparts of these highly conserved RNA polymerase-associated proteins (J. Dasen and M. Rosenfeld, unpubl.). Genetic approaches actively link some Tup1 repression events to the yeast homologs of class I (Rpd3) and class II (HDA1) HDACs, and Drosophila Groucho can interact with dRpd3 (Kuchin and Carlson 1998; Gromoller and Lehming 2000; Watson et al. 2000; Wu et al. 2001), however, we also do not find high-affinity interactions between TLE1 and mammalian HDAC1-HDAC6. Although HDACs may be recruited to TLE1 in a substoichiometric fashion, we suggest that cooperative recruitment of HDAC complexes to the homeodomain may be mediated through a TLE1dependent mechanism. TLE1 contains the well-characterized WD40 repeat, which we have documented to be required for interactions with Hesx1, including conserved residues used for protein-protein interactions. The domains $\mathrm{N}$-terminal to the WD40 repeats are critical for repression by TLE1; therefore, it is possible that a complex containing several components is required for TLE1 actions.

Whereas the SWI/SNF complex was initially identified as a critical component of $\mathrm{HO}$ gene activation events, subsequent genetic studies have revealed that activation of components of this complex have effects on both gene activation and repression (for review, see Sudarsanam and Winston 2000); one initial suggestion was that at least some repression events reflected activation of gene-specific repressors. Our data concerning Hesx1 supports the idea that components of the mammalian SWI/ SNF complex (including Brg-1, BAF 51, BAF155, and BAF170) can be recruited and might serve as a required component of repression in cases in which the HDACdependent machinery recruited by the homeodomain is required. Recent biochemical purification of the Brg1 complex revealed the presence of Sin3A/B and HDAC1 (Sif et al. 2001). This is consistent with a model in which chromatin remodeling is an important component of both repression and activation, and we suggest that, as was found to be also required for other classes of repressors including nuclear receptors, this complex exerts its role in repression by recruiting many classes of DNA-binding factors. Formal documentation in the case of Hesxl will require the identification of the critical target genes.

In summary, we have provided evidence for the importance of coordinated regulation of a repressor (Hesx1) and corepressor (TLE1) as a determinant of organ determination and the temporal control in the generation of pituitary cell lineages. The synergy between TLE and N-CoR complexes, recruited by separate domains, may underlie the strong repressor actions of Hesx1. Further, our data suggest that sequential repression and activation of a common set of regulatory genes may prove to be an underlying strategy in the temporal code of pituitary organ development, with initial repression required for organ commitment and proliferation, and subsequent activation for commitment of specific cell lineages.

\section{Material and methods}

Generation and analysis of transgenic animals

Genotype analysis of $\mathrm{Hes} \times 1^{-/-}$and Prop- $1^{\mathrm{df}}$ mice and generation of transgenic have been described previously (Sornson et al. 1996; Dattani et al. 1998; Treier et al. 1998). Founder animals were analyzed for integration by PCR and Southern blot analysis. All transgenic animals used in this study were determined to have integrated $\sim 3-10$ copies of the transgene and were obtained from embryonic founders. The following number of positive founders were analyzed for each construct: $\alpha$ GSU/Hesx 1 , $n=5 ;$ Pitx1/Hesx1, $n=5$; Pitx1/Prop-1, $n=4$; Pitx1/FGF8, $n=4$; Pitx1/Hesx1:Pitx1/TLE1, $n=5$; Pitx1/Hesx1eh1mut:Pitx1/TLE, $n=3$. For generation of double-transgenic embryos, DNAs were mixed at a 1:1 molar ratio prior to injection.

\section{In situ hybridization and immunohistochemistry}

In situ hybridization and immunohistochemistry was performed as described previously (Simmons et al. 1990; Dasen et al. 1999).

\section{Transfection and nuclear microinjection assays}

Cotransfection experiments were performed as described previously (Rhodes et al. 1993) in 293T and COS-7 cells, using $1 \mu \mathrm{g}$ of luciferase reporter, 50-500 ng of pCMX expression plasmids, and $500 \mathrm{ng}$ of pRSV $\beta \mathrm{Gal}$ as an internal control for differences in transfection efficiencies. The 4XPrdQ/tk luciferase reporter was generated by multimerization of annealed oligonucleotides containing a paired-like binding site $\left(5^{\prime}\right.$-TAATTGAATTA- $\left.3^{\prime}\right)$ and cloned upstream of the thymidine kinase promoter in luciferase and lac $Z$ reporter plasmids. Microinjection of reporter plasmids and IgG-purified antibodies staining for $\beta$-galactosidase activity and fluorescence microscopy analysis was performed essentially as described (Jepsen et al. 2000).

\section{Characterization of Hesx1 interacting proteins from HeLa nuclear extracts}

Frozen pellets of HeLa cells, corresponding to $20 \mathrm{~L}$ of spinner cultures were obtained from the National Cell Culture Center. HeLa nuclear extracts were prepared by standard methods (Dignam et al. 1983). For interaction studies, $0.75-1 \mathrm{mg}$ of HeLa nuclear extracts were precleared twice with $50 \mu \mathrm{L}$ of GST-saturated glutathione agarose beads, each at $4^{\circ} \mathrm{C}$ for $1 \mathrm{~h}$ and then combined with 10-50 $\mu$ g of immobilized GST-Hesx1 fragments at $4^{\circ} \mathrm{C}$ for $3 \mathrm{~h}$. The beads were washed four times with binding buffer (20 mM Tris at pH 7.8, $150 \mathrm{mM} \mathrm{NaCl}, 0.1 \% \mathrm{NP} 40,10 \%$ glycerol, $0.5 \mathrm{mM}$ EDTA) and the protein complexes were then eluted twice at $4{ }^{\circ} \mathrm{C}$ in binding buffer containing $0.3 \%$ Sarkosyl for $1 \mathrm{~h}$ each. The eluates were pooled and complexes separated on a $5 \%-15 \%$ gradient SDS-polyacrylamide gel and transferred to nitrocellulose membranes for Western blotting. All antibodies used in these studies were obtained from Santa Cruz Biotechnology and used at a 1:2000-1:5000 dilution. HDAC assays were performed as described (Hoffmann et al. 1999), using material purified from $500 \mu \mathrm{g}$ of HeLa nuclear extracts.

\section{Coimmunoprecipitations and protein-interaction assays}

Coimmunoprecipitation and other protein-interaction studies were performed as described previously (Dasen et al. 1999). Whole-cell lysates were incubated with $1 \mu \mathrm{L}$ of anti-FLAG M2 monoclonal antibody (Sigma) for $30 \mathrm{~min}$ on ice, precipitated with Protein $\mathrm{A} / \mathrm{G}$ plus agarose at $4^{\circ} \mathrm{C}$ for $2 \mathrm{~h}$, and washed four 
times in binding buffer. Complexes were resolved by SDS-PAGE and transferred to nitrocellulose membranes. TLE1 was detected by use of a polyclonal antibody (SantaCruz Biotechnology) at a 1:3000 dilution, followed by anti-rabbit HRP-coupled secondary antibodies (Jackson Immuno Research) at 1:5000, and developed by ECL (Amersham).

Fragments encoding subdomains of Hesx1 and TLE1 were generated by PCR amplification and cloned in frame into the GST expression plasmid pGEX2TK (Pharmacia) or into the plasmid pCDNA3-KATG for in vitro transcription and translation from rabbit reticulocyte lysates using ${ }^{35}$ S-labeled methionine (Promega). Point mutations in Hesx 1 and TLE1 were generated using the Quick Change Mutagenesis kit (Stratagene) and were confirmed by DNA sequencing.

\section{Acknowledgments}

We thank Rosa Beddington and Ian C.A.F. Robinson for providing Hesx 1 mutant mice. We also thank P. Meyer for expertise in preparation of illustrations and M. Fisher for manuscript preparation. For technical assistance, we thank the UCSD Transgenic Core Facility, C. Nelson for cell culture, and H. Taylor for animal care. J.S.D is supported by a fellowship from the National Institutes of Health. M.G.R is an Investigator with the Howard Hughes Medical Institute. This work was supported by NIH (NIDDK) grants to M.G.R.

The publication costs of this article were defrayed in part by payment of page charges. This article must therefore be hereby marked "advertisement" in accordance with 18 USC section 1734 solely to indicate this fact.

\section{References}

Chen, G. and Courey, A.J. 2000. Groucho/TLE family proteins and transcriptional repression. Gene 249: 1-16.

Chen G., Nguyen, P.H., and Courey, A.J. 1998. A role for Groucho tetramerization in transcriptional repression. Mol. Cell. Biol. 18: 7259-7268.

Chen, G., Fernandez, J., Mische, S., and Courey, A.J. 1999. A functional interaction between the histone deacetylase Rpd3 and the corepressor groucho in Drosophila development. Genes \& Dev. 13: 2218-2230.

Cushman, L.J., Watkins-Chow, D.E., Brinkmeier, M.L., Raetzman, L.T., Radak, A.L., Lloyd, R.V., and Camper, S.A. 2001. Persistent Prop1 expression delays gonadotrope differentiation and enhances pituitary tumor susceptibility. Hum. Mol. Genet. 10: 1141-1153.

Dasen, J.S. and Rosenfeld, M.G. 2001. Signaling and transcriptional mechanisms in pituitary development. Annu. Rev. Neurosci. 24: 327-355.

Dasen, J.S., O'Connell, S.M., Flynn, S.E., Treier, M., Gleiberman, A.S., Szeto, D.P., Hooshmand, F., Aggarwal, A.K., and Rosenfeld, M.G. 1999. Reciprocal interactions of Pit1 and GATA2 mediate signaling gradient induced determination of pituitary cell types. Cell 97: 587-598.

Dattani, M.T., Martinez-Barbera, J.P., Thomas, P.Q., Brickman, J.M., Gupta, R,. Martensson, I.L., Toresson, H., Fox, M., Wales, J.K., Hindmarsh, P.C., et al. 1998. Mutations in the homeobox gene HESX1/Hesx1 associated with septo-optic dysplasia in human and mouse. Nat. Genet. 19: 125-133.

Dignam, J.D., Lebovitz, R.M., and Roeder, R.G. 1983. Accurate transcription initiation by RNA polymerase II in a soluble extract from isolated mammalian nuclei. Nucleic Acids Res. 11: 1475-1489.
Eberhard, D., Jimenez, G., Heavey, B., and Busslinger, M. 2000. Transcriptional repression by Pax 5 (BSAP) through interaction with corepressors of the Groucho family. EMBO J. 19: 2292-2303.

Ericson, J., Norlin, S., Jessell, T., and Edlund, T. 1998. Integrated FGF and BMP signaling controls the progression of progenitor cell differentiation and the emergence of pattern in the embryonic anterior pituitary. Development 125: 1005-1015.

Gage, P.J., Brinkmeier, M.L., Scarlett, L.M., Knapp, L.T., Camper, S.A., and Mahon, K.A. 1996. The Ames dwarf gene, df, is required early in pituitary ontogeny for the extinction of Rpx transcription and initiation of lineage-specific cell proliferation. Mol. Endocrinol. 10: 1570-1581.

Gromoller, A. and Lehming, N. 2000. Srb7p is a physical and physiological target of Tup1p. EMBO J. 19: 6845-6852.

Guenther, M.G., Lane, W.S., Fischle, W., Verdin, E., Lazar, M.A., and Shiekhattar, R. 2000. A core SMRT corepressor complex containing HDAC3 and TBL1, a WD40-repeat protein linked to deafness. Genes \& Dev. 14: 1048-1057.

Hermesz, E., Mackem, S., and Mahon, K.A. 1996. Rpx: A novel anterior-restricted homeobox gene progressively activated in the prechordal plate, anterior neural plate and Rathke's pouch of the mouse embryo. Development 122: 41-52.

Hoffmann, K., Brosch, G., Loidl, P., and Jung, M. 1999. A nonisotopic assay for histone deacetylase activity. Nucleic Acids Res. 27: 2057-2058.

Jepsen, K., Hermanson, O., Onami, T.M., Gleiberman, A.S., Lunyak, V., McEvilly, R.J., Kurokawa, R., Kumar, V., Liu, F., Seto, E., et al. 2000. Combinatorial roles of the nuclear receptor corepressor in transcription and development. Cell 102: 753-763.

Jimenez, G., Paroush, Z., and Ish-Horowicz, D. 1997. Groucho acts as a corepressor for a subset of negative regulators, including Hairy and Engrailed. Genes \& Dev. 11: 3072-3082.

Komachi, K. and Johnson, A.D. 1997. Residues in the WD repeats of Tup1 required for interaction with alpha2. Mol. Cell. Biol. 17: 6023-6028.

Kuchin, S. and Carlson, M. 1998. Functional relationships of Srb10-Srb11 kinase, carboxy-terminal domain kinase CTDK-I, and transcriptional corepressor Ssn6-Tup1. Mol. Cell. Biol. 18: 1163-1171.

Laherty, C.D., Billin, A.N., Lavinsky, R.M., Yochum, G.S., Bush, A.C., Sun, J.M., Mullen, T.M., Davie, J.R., Rose, D.W., Glass, C.K., et al. 1998. SAP30, a component of the $\mathrm{mSin} 3$ corepressor complex involved in N-CoR-mediated repression by specific transcription factors. Mol. Cell 2: 33-42.

Martinez-Barbera, J.P., Rodriguez, T.A., and Beddington, R.S. 2000. The homeobox gene Hesx 1 is required in the anterior neural ectoderm for normal forebrain formation. Dev. Biol. 223: 422-430.

Muhr, J., Andersson, E., Persson, M., Jessell, T.M., and Ericson, J. 2001. Groucho-mediated transcriptional repression establishes progenitor cell pattern and neuronal fate in the ventral neural tube. Cell 104: 861-873.

Paroush, Z., Finley, R.L., Jr., Kidd, T., Wainwright, S.M., Ingham, P.W., Brent, R., and Ish-Horowicz, D. 1994. Groucho is required for Drosophila neurogenesis, segmentation, and sex determination and interacts directly with hairy-related bHLH proteins. Cell 79: 805-815.

Ren, B., Chee, K.J., Kim, T.H., and Maniatis, T. 1999. PRDIBF1/Blimp-1 repression is mediated by corepressors of the Groucho family of proteins. Genes \& Dev. 13: 125-137.

Rhodes, S.J., Chen, R., DiMattia, G.E., Scully, K.M., Kalla, K.A., Lin, S.C., Yu, V.C., and Rosenfeld, M.G. 1993. A tissue-specific enhancer confers Pit-1-dependent morphogen inducibility and autoregulation on the pit-1 gene. Genes \& Dev. 
7: 913-932.

Sheng, H.Z. and Westphal, H. 1999. Early steps in pituitary organogenesis. Trends Genet. 15: 236-240.

Sheng, H.Z., Zhadanov, A.B., Mosingerm B., Jr., Fujii, T., Bertuzzi, S., Grinberg, A., Lee, E.J., Huang, S.P., Mahon, K.A., and Westphal, H. 1996. Specification of pituitary cell lineages by the LIM homeobox gene Lhx3. Science 272: 10041007.

Sif, S., Saurin, A.J., Imbalzano, A.N., and Kingston, R.E. 2001. Purification and characterization of mSin3A-containing Brg1 and hBrm chromatin remodeling complexes. Genes \& Dev. 15: 603-618.

Simmons, D.M., Voss, J.W., Ingraham, H.A., Holloway, J.M., Broide, R.S., Rosenfeld, M.G., and Swanson, L.W. 1990. Pituitary cell phenotypes involve cell-specific Pit-1 mRNA translation and synergistic interactions with other classes of transcription factors. Genes \& Dev. 4: 695-711.

Smith, S.T. and Jaynes, J.B. 1996. A conserved region of engrailed, shared among all en-, gsc-, Nk1-, Nk2-, and mshclass homeoproteins, mediates active transcriptional repression in vivo. Development 122: 3141-3150.

Sornson, M.W., Wu, W., Dasen, J.S., Flynn, S.E., Norman, D.J., O'Connell, S.M., Gukovsky, I., Carriere, C., Ryan, A.K., Miller, A.P., et al. 1996. Pituitary lineage determination by the Prophet of Pit-1 homeodomain factor defective in Ames dwarfism. Nature 384: 327-333.

Sprague, E.R., Redd, M.J., Johnson, A.D., and Wolberger, C. 2000. Structure of the C-terminal domain of Tup1, a corepressor of transcription in yeast. EMBO J. 19: 3016-3027.

Stifani, S., Blaumueller, C.M., Redhead, N.J., Hill, R.E., and Artavanis-Tsakonas, S. 1992. Human homologs of a Drosophila Enhancer of split gene product define a novel family of nuclear proteins. Nat. Genet. 2: 119-127.

Sudarsanam, P. and Winston, F. 2000. The Swi/Snf family nucleosome-remodeling complexes and transcriptional control. Trends Genet. 16: 345-351.

Thomas, P.Q., Dattani, M.T., Brickman, J.M., McNay, D., Warne, G., Zacharin, M., Cameron, F., Hurst, J., Woods, K., Dunger, D., et al. 2001. Heterozygous HESX1 mutations associated with isolated congenital pituitary hypoplasia and septo-optic dysplasia. Hum. Mol. Genet. 10: 39-45.

Tolkunova, E.N., Fujioka, M., Kobayashi, M., Deka, D., and Jaynes, J.B. 1998. Two distinct types of repression domain in engrailed: One interacts with the groucho corepressor and is preferentially active on integrated target genes. Mol. Cell. Biol. 18: 2804-2814.

Treier, M., Gleiberman, A.S., O'Connell, S.M., Szeto, D.P., McMahon, J.A., McMahon, A.P., and Rosenfeld, M.G. 1998. Multistep signaling requirements for pituitary organogenesis in vivo. Genes \& Dev. 12: 1691-1704.

Treier, M., O'Connell, S., Gleiberman, A., Price, J., Szeto, D.P., Burgess, R., Chuang, P.T., McMahon, A.P., and Rosenfeld, M.G. 2001. Hedgehog signaling is required for pituitary gland development. Development 128: 377-386.

Underhill, C., Qutob, M.S., Yee, S.P., and Torchia, J. 2000. A novel nuclear receptor corepressor complex, N-CoR, contains components of the mammalian SWI/SNF complex and the corepressor KAP-1. J. Biol. Chem. 275: 40463-40470.

Watson, A.D., Edmondson, D.G., Bone, J.R., Mukai, Y., Yu, Y., Du, W., Stillman, D.J., and Roth, S.Y. 2000. Ssn6-Tup1 interacts with class I histone deacetylases required for repression. Genes \& Dev. 14: 2737-2744.

Wilson, D., Sheng, G., Lecuit, T., Dostatni, N., and Desplan, C. 1993. Cooperative dimerization of paired class homeo domains on DNA. Genes \& Dev. 7: 2120-2134.

Wu, J., Suka, N., Carlson, M., and Grunstein, M. 2001. TUP1 utilizes histone $\mathrm{H} 3 / \mathrm{H} 2 \mathrm{~B}$-specific HDA1 deacetylase to repress gene activity in yeast. Mol. Cell. 7: 117-126.

Wu, W., Cogan, J.D., Pfaffle, R.W., Dasen, J.S., Frisch, H., O'Connell, S.M., Flynn, S.E., Brown, M.R., Mullis, P.E., Parks, J.S., et al. 1998. Mutations in PROP1 cause familial combined pituitary hormone deficiency. Nat. Genet. 18: $147-149$.

Xu, L., Lavinsky, R.M., Dasen, J.S., Flynn, S.E., McInerney, E.M., Mullen, T.M., Heinzel, T., Szeto, D., Korzus, E., Kurokawa, R., et al. 1998. Signal-specific co-activator domain requirements for Pit-1 activation. Nature 395: 301-306. 


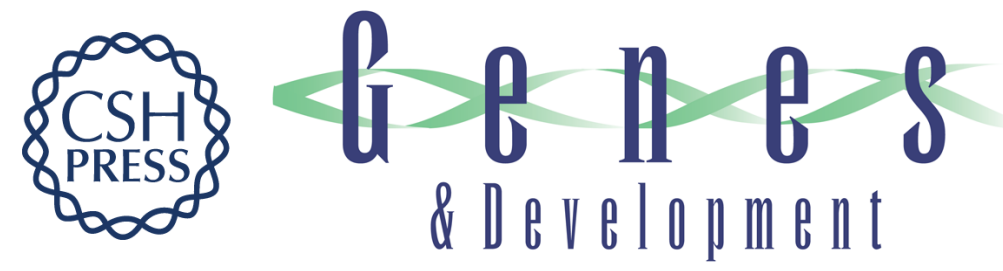

\section{Temporal regulation of a paired-like homeodomain repressor/TLE corepressor complex and a related activator is required for pituitary organogenesis}

Jeremy S. Dasen, Juan-Pedro Martinez Barbera, Thomas S. Herman, et al.

Genes Dev. 2001, 15:

Access the most recent version at doi:10.1101/gad.932601

References This article cites 44 articles, 23 of which can be accessed free at:

http://genesdev.cshlp.org/content/15/23/3193.full.html\#ref-list-1

License

Email Alerting

Service

Receive free email alerts when new articles cite this article - sign up in the box at the top right corner of the article or click here.

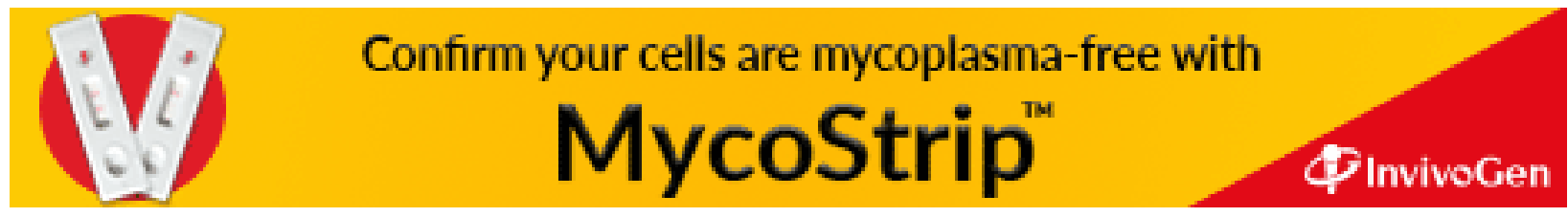

